\title{
Glass Fibre Reinforcements in Concrete
}

\author{
Tanveer Singh Ahuja ${ }^{1}$, Abhinav Panwar ${ }^{2}$ \\ ${ }^{1,2}$ Department of Civil Engineering, G.L.Bajaj Institute of Technology and Management, Greater Noida, Uttar Pradesh, India
}

\begin{abstract}
Concrete is the most primarily used material in the construction field followed by steel as reinforcements. The present day scenario is witnessing a fast change in the building material industry and day by day new technologies are replacing the conventionally used materials. Researchers all over the world are working hard to improve concrete by the use of fibres, pozzolanas and other admixtures. Steel is provided in the compression side primarily so as to counter act the weak zone of concrete that is Tension. Though it is considered to be the best for this work but still it gets corroded by the action of the nature thus, arises the topic of looking for a alternative. One of the most common alternatives is Fibre reinforced polymer rebars (FRP's). In the present experimental investigation two processes are combined (I) replacement of Ordinary Concrete with Glass fibre Reinforced Concrete and (II) replacement of ordinary steel rebars with Glass fibre polymer rebars(GFRP's) and thus studied on the changes of Compressive Strength and Ultimate Crushing loads.
\end{abstract}

Keywords: GFRP, FRP, Glass fibre, Concrete, RCC

\section{Introduction}

Concrete is on the most commonly used building material. It is basically the foundation of real estate and infra industry. It has various strengths such as high compressive strength, stiffness, temperature endurance and durability. It can be easily casted when and where required and also its raw materials are easily available. On the other hand it is brittle and weak in tension which is considered to be the shortcomings of the concrete. Though generally Reinforcements are used concrete that is the concrete is reinforced by steel in the tension region in order to increase its strengths in tension.

\subsection{Glass Fibre Reinforced Concrete (GFRC)}

Fibre Reinforced Concrete is a concrete made in the same manner as the ordinary concrete but it contains fibre material which is spread evenly in the complete concrete mix. Alkali resistant fibres are most commonly used for GFRC. It is a new technology. It is basically added in to water used for making the mix. Once the fibre is properly spread it forms a mesh like network. This forms a matrix of evenly mixed fibres forming a random distribution of fibres having high tensile strength. Due to this mesh the cracking strengths of the concrete increases and thus the fibres acts as crack arresters.

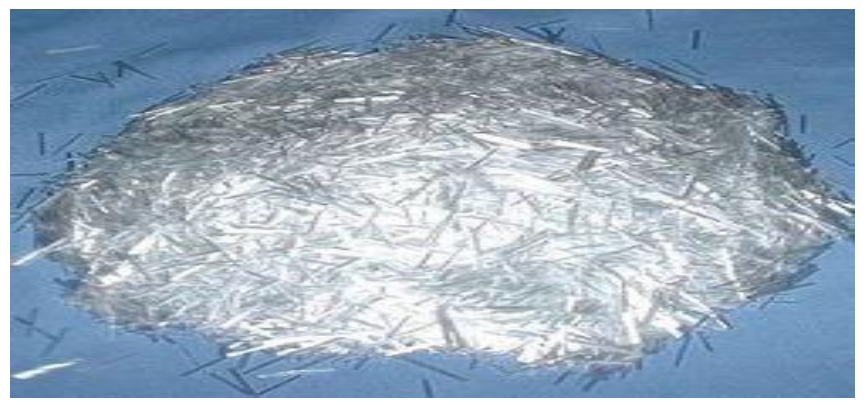

Figure 1: Glass fibres $12 \mathrm{~mm}$ long

Various percentages of fibre content in the concrete had been studied on lately and it was observed that more the fibre content more will be the cracking and tensile strengths.
Generaly $5 \%$ fibre content is used, that is $5 \%$ of the weight of total cementious material. Glass fibres are produced in process in which the molten glass is drawn into the this fibres. The molten glass is drawn into thin filaments with are later cut into $12 \mathrm{~mm}$ and $6 \mathrm{~mm}$ fibre which are then used in the GFRC.

\subsection{Glass Fibre Reinforced Polymers (GFRP):}

Steel bars are the commonly used reinforcements in the RCC. They are cost efficient and effective only if they are not subjected to chloride ion attack and other attacks of nature.

They are subjected to oxidation when exposed to moisture and other chemicals. When such corrosion occurs the volume of the bar increases up to 2 to 5 times, as the concrete cannot withstand this tensile stresses it cracks ultimately causing failure. Thus, this deterioration and loss leads to steel replacement which is expensive and not feasible. The advantageous property of GFRP like high resistance to corrosion and other chemical agents, high tensile strengths and fatigue resistance have grabbed the attention of the engineers.

The GFRP rebar have high tensile strength and are extremely resistant to natural and chemical agents. There strengths are reliable and repeatable and thus, it is comparable to steel bars. The beams having GFRP bars as shear reinforcement are able to withstand more shear strengths and thus it is comparable to steel bars.

The GFRP bars are brittle in nature thus there stress-strain graph shows immediate failure but the beams casted using GFRP bars do not fail suddenly thus it is safe and gives proper warning before collapsing. Still to avoid catastrophic failures GFRP beams are designed using working stress method.

They are available in various sizes just like steel bars from 12 $\mathrm{mm}$ to $40 \mathrm{~mm}$ dia. 




Figure 2: Glass fibre reinforced concrete

\section{Technical Specifications}

\subsection{Glass Fibres}

- Filament diameter - $14 \mu$

- Specific gravity- 2.6

- Length- $12 \mathrm{~mm}$

- Density $\left(\mathrm{t} / \mathrm{m}^{3}\right)-2.6$

- Elastic modulus- 73

- Tensile strength- 1700

- No of fibres (million/kg)-220

\subsection{Glass Fibre reinforced polymer (GFRP):}

- Guage Length (Lo) $80.0000 \mathrm{~mm}$

- Final Guage Length $82.5000 \mathrm{~mm}$

- Inner Dia $0.0000 \mathrm{~mm}$

- Outer Dia 16.0000 mm.

- Area $201.1392 \mathrm{~mm}^{2}$

- Maximum Load $141.831 \mathrm{kN}$

- Strain $5.000 \%$

- U.T.S. Value $705.139 \mathrm{~N} / \mathrm{mm}^{2}$

- Mod. of Elasticity $46620.000 \mathrm{~N} / \mathrm{mm}^{2}$

- $0.2 \%$ Proof Load $94.420 \mathrm{kN}$

- Stress @ 0.2\% Prf. Load 469.430 N I mm ${ }^{2}$

- Yield Load 19.966 kN

- Yield Stress $99.263 \mathrm{~N} / \mathrm{mm}^{2}$

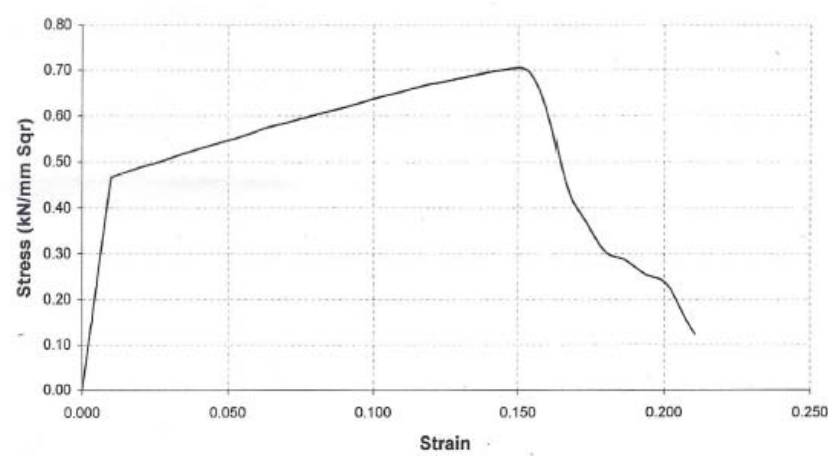

Figure 3: Stress-Strain graph of GFRP

\section{Methodology For Experimentation}

\subsection{Testing of material}

All the materials such as course aggregates, fine aggregates and cement were tested were tested for their specific gravity.

- Specific gravity of cement- 2.2

- Specific gravity of fine aggregate- 2.8

- Specific gravity of course aggregate- 2.54

\subsection{Casting of beam and cubes}

Beams and cubes are casted from the same concrete mix so that the results obtained are comparable. The moulds used to cast beams are of size $2000 * 260 * 240 \mathrm{~mm}$ in dimensions. And the moulds for cubes are $150 * 150 * 150 \mathrm{~mm}$ in dimesions. The beams were reinforced with $16 \mathrm{~mm}$ main reinforcement and $8 \mathrm{~mm}$ hanger bars are provided to facilitate the erection process.

4 beams and total 12 cubes were casted, 6 cubes from the normal concrete and 6 cubes from glass fibre reinforced concrete. Out this half were used for 7 day testing and half for 28 days testing. The beams were checked after 28 days of proper curing.

\subsubsection{Different types of Beams}

Four different types of test beams were casted so as to study all the types of combinations possible with the available material. The different cases were:

- Plain concrete with Steel rebars (Beam1)

- Glass fibre reinforced concrete with steel rebars (Beam2)

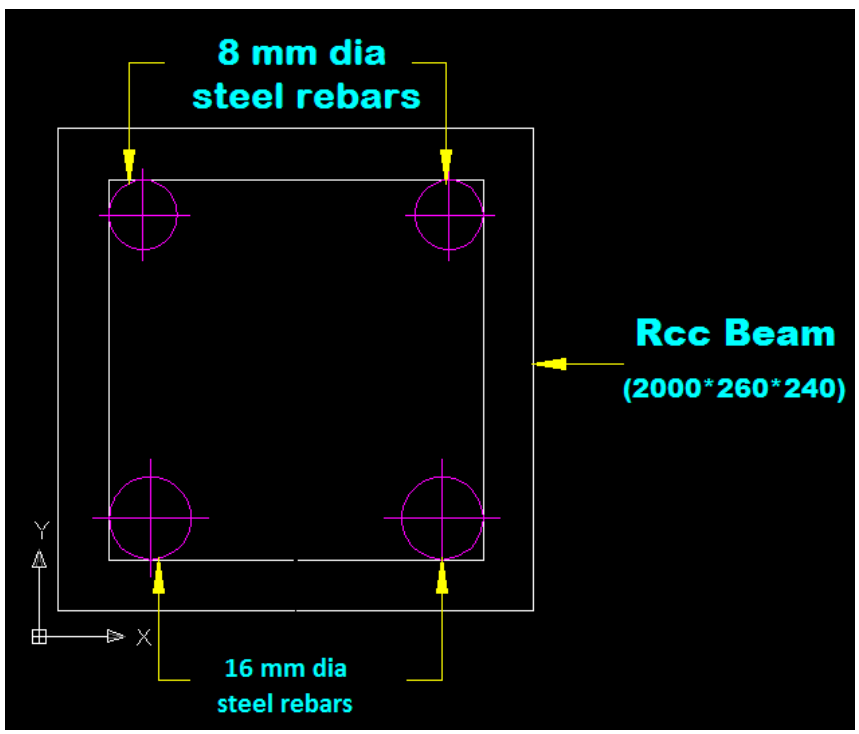

Figure 4: Drawing of r/f provided in beam $1 \& 2$

- Plain concrete with glass fibre reinforced polymer rebars (Beam3)

- Glass fibre reinforced concrete with glass fibre reinforced polymer rebars (Beam4) 


\section{International Journal of Science and Research (IJSR)}

ISSN (Online): 2319-7064

Index Copernicus Value (2013): 6.14 | Impact Factor (2014): 5.611

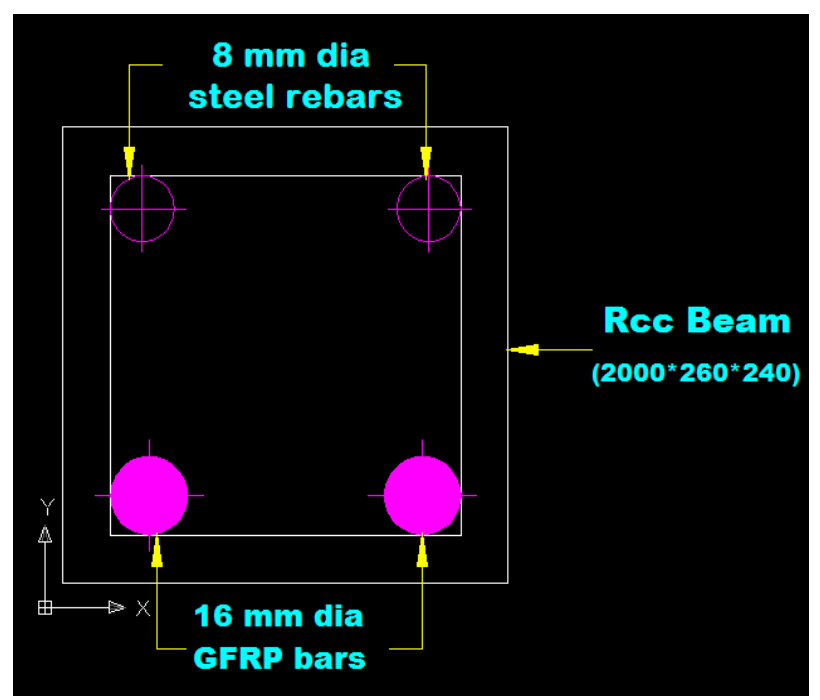

Figure 5: Drawing of r/f provided in beam 1\&2

\subsubsection{Types of concrete}

- Ordinary concrete

Standard mix design for M25 was properly designed according to IS10262:2009 and was further adjusted according to prevailing moisture content of the raw material batch.

\begin{tabular}{|c|c|c|c|c|c|c|c|}
\hline Description & Units & CA1 & CA2 & FA & Water & Cement & Remarks \\
\hline $\begin{array}{c}\text { Wt. of wet } \\
\text { sample }\end{array}$ & Gms. & 1000 & 1000 & 1000 & & & \\
\hline $\begin{array}{c}\text { Wt. of dried } \\
\text { Sample }\end{array}$ & Gms. & 994 & 995 & 955 & & & \\
\hline Wt. of Moisture & $\%$ & 6 & 5 & 45 & & & \\
\hline Moisture & $\%$ & 0.60 & 0.50 & 4.71 & & & \\
\hline Absorption & $\%$ & 0.32 & 0.34 & 0.66 & & & \\
\hline Free Nioisture & $\%$ & 0.28 & 0.16 & 4.05 & & & \\
\hline Batch Wt. & Kgs. & 215 & 92 & 188 & 40 & 85 & \\
\hline Free Moisture & Kgs. & 0.61 & 0.15 & 7.62 & 8.38 & & \\
\hline Adjusted Wt. & Kgs. & 215.61 & 92.15 & 195.62 & 31.62 & 85 & \\
\hline Wt. Adopted & Kgs. & 216 & 92 & 196 & 32 & 85 & \\
\hline
\end{tabular}

Figure 6: Parameters used in the mix design

- Glass fibre reinforced concrete:

Glass fibres are added up to $5 \%$ of the total weight of cementeous material. The fibres are mixed with water and stirred till the form a mesh like look. Later this water is used in making concrete.

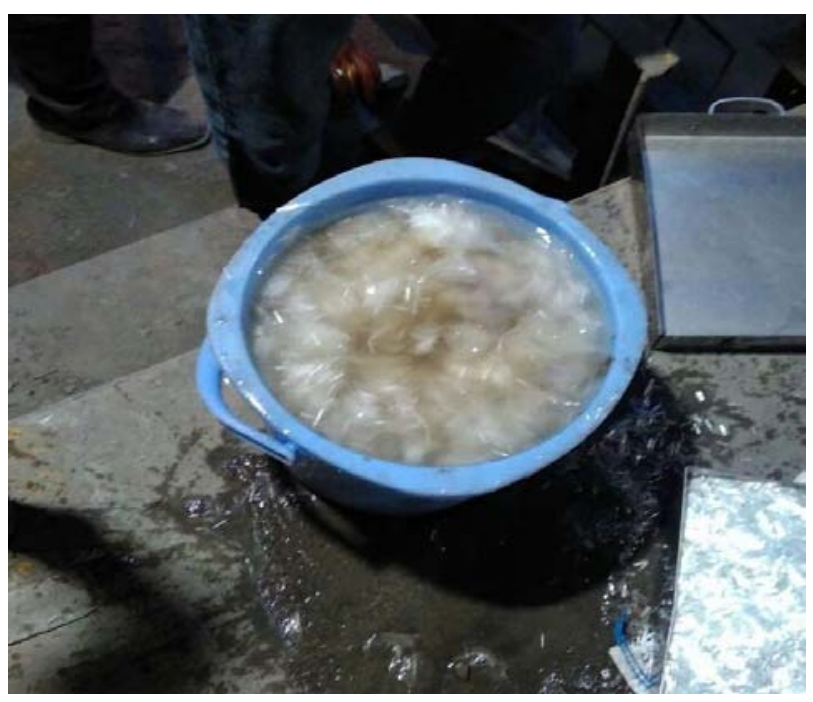

Figure 7: Glass fibre forming mesh when added to water

\section{Test Results}

\subsection{Compression test}

The cubes were tested for their compressive strength after 7 days and also after 28 days of curing.

Compressive strength: it is that strengths which enables a mass to resist the loads tending to reduce sizes.

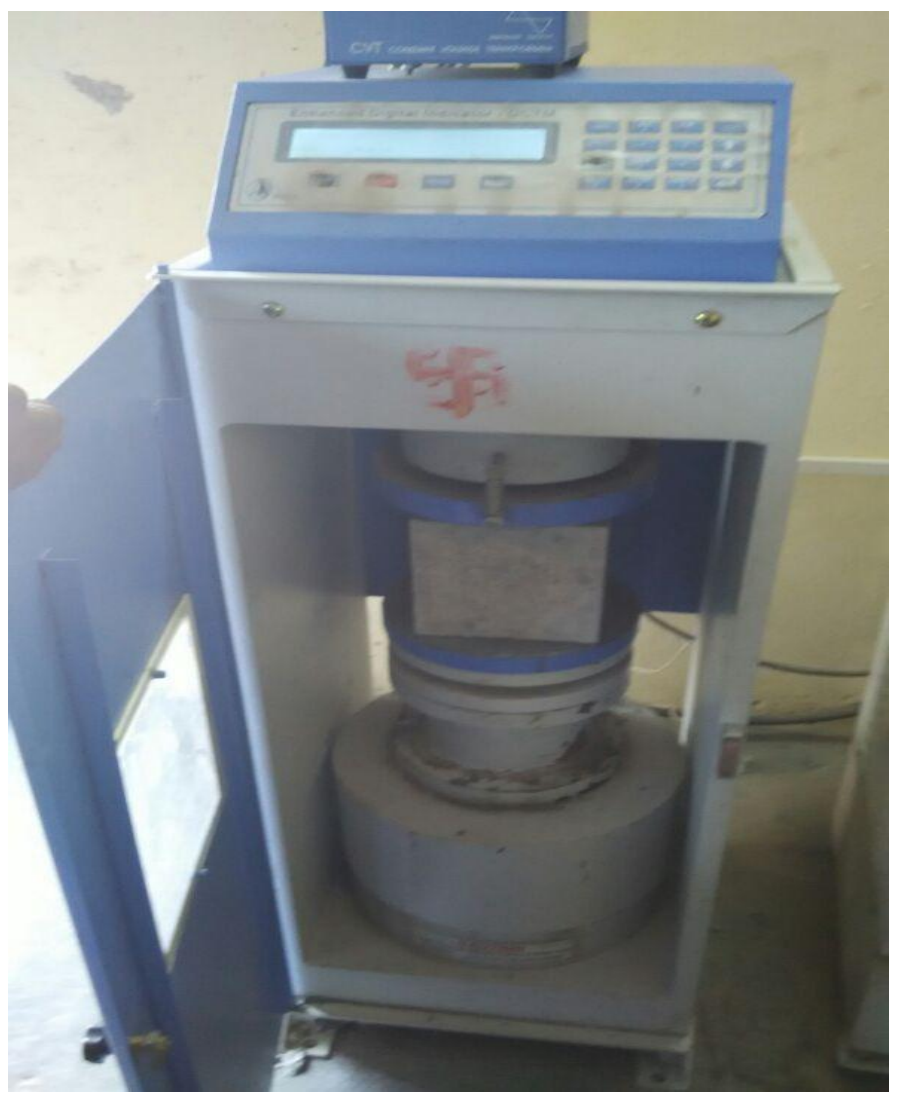

Figure 8: Compression Testing Machine 


\section{International Journal of Science and Research (IJSR) \\ ISSN (Online): 2319-7064}

Index Copernicus Value (2013): 6.14 | Impact Factor (2014): 5.611

Table 1: Test Results for compression test

\begin{tabular}{|c|c|c|c|c|c|}
\hline $\begin{array}{c}\text { Sample } \\
\text { No. }\end{array}$ & Type & Days & $\begin{array}{c}\text { Ultimate Load } \\
(\mathrm{KN})\end{array}$ & $\begin{array}{c}\text { Comp. } \\
\text { Stre. }\left(\mathrm{N} / \mathrm{mm}^{2}\right)\end{array}$ & Mean \\
\hline 1 & ORD & 7 & 398 & 17.689 & \\
\hline 2 & ORD & 7 & 357 & 15.867 & 16.8 \\
\hline 3 & ORD & 7 & 385 & 17.111 & \\
\hline 1 & GFRC & 7 & 452 & 20.089 & \\
\hline 2 & GFRC & 7 & 448 & 19.911 & 20.1 \\
\hline 3 & GFRC & 7 & 461 & 20.489 & \\
\hline 1 & ORD & 28 & 771.3 & 34.280 & \\
\hline 2 & ORD & 28 & 697.6 & 31.004 & 32.2 \\
\hline 3 & ORD & 28 & 704.3 & 31.302 & \\
\hline 1 & GFRC & 28 & 962.9 & 42.796 & \\
\hline 2 & GFRC & 28 & 934.6 & 41.538 & 41.8 \\
\hline 3 & GFRC & 28 & 927.2 & 41.209 & \\
\hline
\end{tabular}

ORD- Ordinary Concrete

GFRC- Glass Fibre Reinforced Concrete

\subsection{Flexure Test (Static Bending Test)}

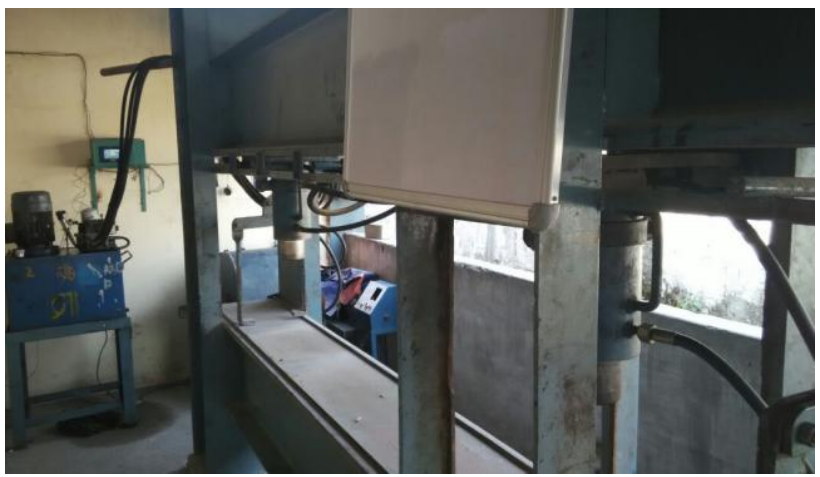

Figure 9: 4 Point Flexure Testing Machine

Flexural strength: it is the measure of a tensile strength of the concrete beam. It tells us the resistance offered by the beam under bending conditions.

The RCC beams were properly cured for 28 days before being tested upon the 4 point flexure test machine. The beam was subjected to 2 loadings from the upper end at distance of $\mathrm{L} / 4$. L/4 distance is used for this purpouse so that true flexural strength can be obtained and rotational torque can be avoided.

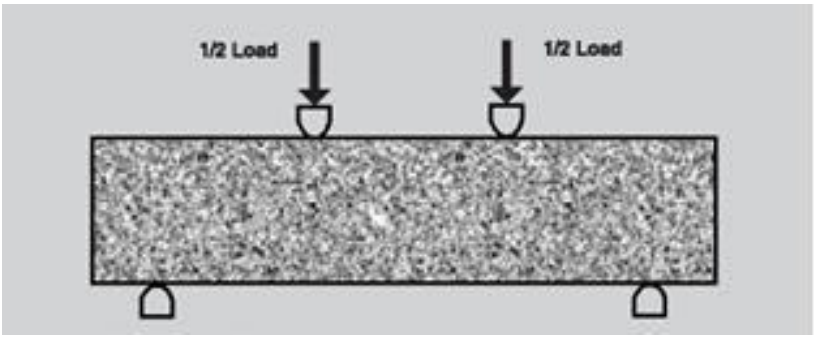

Figure 10: Graphical representation of Loading

Table 2: Test results for 4 point flexure test

\begin{tabular}{|c|c|c|c|}
\hline $\begin{array}{c}\text { Type of } \\
\text { reinforcement }\end{array}$ & $\begin{array}{c}\text { Type of } \\
\text { concrete }\end{array}$ & $\begin{array}{c}\text { Cracking } \\
\text { load }\end{array}$ & $\begin{array}{c}\text { Ultimate } \\
\text { load }\end{array}$ \\
\hline STEEL & NORMAL & 50 & 145 \\
\hline STEEL & GFRC & 55 & 120 \\
\hline GFRP & GFRC & 66 & 199 \\
\hline GFRP & NORMAL & 45 & 212 \\
\hline
\end{tabular}

\section{Observations}

\subsection{Glass Fibre Reinforced concrete:}

- Glass fibres checked on the bleeding in concrete.

- The 7 day compressive strength and also the 28 day compressive strength increased by an adequate amount.

- The voids in the concrete were reduced.

- The tensile strength of concrete also increses due to mesh formation.

- Glass fibres prevent shrinkage cracks.

- Water-cement ratio decreases.

- Air entrainment decreases.

- First cracking load is high in case of beams.

\subsection{Glass Fibre Reinforced Polymer Bars}

- No rust was found

- Chemically stable material.

- Tensile strength considerable increased

- Light weight in nature.

- Ultimate load was very high as compared to conventional reinforcement.

- More allowable deflection.

- Not only flexural strength is increased but also shear capacity and bending moment resisting capacity increases.



Figure 11: 15mm crack termed as first crack

\section{Future Aspects}

- GFRP can be easily used as a replacement of steel reinforcements.

- GFRC claddings are very famous these days.

- GFRC cladding $\mathrm{n}$ designes can be easily repaired and replaced

- Hollow GFRP bars can be used to transmit oil

- GFRP bars can also be used as cooling ducts if required.

- Since being resistant to chemicals and nature's effect they are active replacements

- Sewer pipe lines can be designed and casted using both GFRC and GFRP

- High strength concrete can be worked upon and mixed with GFRC to bring about drastic change in the compressive strength. 


\section{References}

[1] Saint Gobain Vetrotex, Cem - Fil. 2002. Why Alkaline Resistant Glass Fibers. In Technical data sheets.www.cemfil.com

[2] Siva kumar, A. and Santhanam Manu. 2007. Mechanical Properties of High Strength Concrete Reinforced with Metallic and Non-Metallic Fibers. Cement and Concrete Composites (29) pp. 603-608.

[3] Glass Fiber Reinforced Polymer (GFRP) Rebar - Aslan ${ }^{\mathrm{TM}}$ 100 series FIBER GLASS REBAR (2011).

[4] IS Code books IS:10262-2009 and IS:456-2007.

[5] Shapria A, Bank LC. Constructability and economics of FRP reinforced cages for concrete beams. J Compos Constr, ASCE 1997;1(3):82-9.

[6] Nanni A. Flexural behavior and design of RC members using FRP reinforcement. J Struct Engg, ASCE 1993;119(11):3344-55.

[7] Thiagarajan G. Experimental and analytical behavior of carbon fiber based rods as flexural reinforcement. J Compos Constr, ASCE 2003;7(1):64-72.

\section{Author Profile}



Tanveer Singh Ahuja is pursuing his B.Tech (Civil) from D.R A.P.J Abdul Kalam Technical University, formerly known as UPTU. He is currently in his last year and has been admitted to National Institute of Construction Management and Research, Pune for Advance Studies in his field. He wants to be a project manager and also do further research in the field of RCC.

Abhinav Panwar is a student of final year Civil Engineering from D.R A.P.J Abdul Kalam Technical University, formerly known as UPTU. He will be continuing his studies in Advance Construction Management from National Institute of Construction Management and Research (NICMAR), Pune. He want to work in the area of Real Estate so as to make this world a better place to live in. 